\title{
Application of Remote Sensing with R Tool in Validation of PFZ along Coast of Ratnagiri: A Survey
}

\author{
Mr. Swanand U. Mane ${ }^{1}$, Dr. Abhilasha D. Mishra ${ }^{2}$ \\ ${ }^{I}$ Department of Electronics and Telecommunication, M.I.T College, Dr.B.A.M.University, Aurangabad, India. \\ ${ }^{2}$ Department of Electronics and Telecommunication, M.I.T College, Dr.B.A.M.University, Aurangabad, India.
}

\begin{abstract}
Image Processing and Remote Sensing Technologies are the most efficient technologies to give the accurate processed data for Potential Fishing Zone (PFZ). INCOIS which is the governing body for ocean related parameters provides satellite derived data obtained from Electronic Digital Display Board (EDB) and Wave Rider Buoy (WRB). These data which is obtained from EDB and WRB is used for gaining Sea Surface Temperature (SST) and Ocean Color in real time mode. By taking the feedbacks from active fishermen at selected major fish landing centers near Ratnagiri $R$ Tool Technology is used for finding PFZ location to get good catch in less time and fuel. Ratnagiri has a coast line of $237 \mathrm{kms}$ and altitude range of $11 \mathrm{~m}$ having latitudinal position of $16.98^{\circ} \mathrm{N}$ and longitudinal position of $73.3^{\circ} \mathrm{E}$. With view to validate the advisories and to adapt new technology for PFZ location we have discussed $R$ Tool for betterment of fishermen community. This paper will also be useful to understand the food chain and to study different ocean related parameters to do data analysis for long time period and for coastal zone management.
\end{abstract}

Keywords: EDB, WRB, NOAAAVHRR, MODIS, ESRI, ENVI, ERDAS, PFZ.

\section{Introduction}

India is very rich in coastal and marine environment due to which the annual marine fisheries production is 2.94 million tons against the harvestable potential of 3.93 million tons. Indian shares in world fish production has increased from $4.2 \%$ during the last decade [1]. Primary productivity involves the synthesis of organic materials from inorganic substances by photosynthesis. Phytoplankton's make roughly $50 \%$ of the food made by photosynthesis on earth [2]. The role of wind and wave measurement is important for the operation and validation of wave models. It can be divided into 2 categories: - Operational systems designed to provide continuous, global or regional observation for forecasting, data assimilation and model validation. Wind and wave measurement systems operated with higher temporal and spatial resolution during limited measurement campaigns in order to study the physical process of wave generation and air/sea interaction. There are few image processing techniques from which SST and Chlorophyll can be calculated to locate potential fishing zone for this hyper spectral data is required by which the image processing algorithm is obtained. Hyper spectral image are produced by instruments called imaging spectrometers. Among the various countries, the fisheries forecasting system is most well organized in Japan. In India, the methodology for predicting potential zone for fishing was evolved at Space Application Center, Ahmadabad. By studying SST data from NOAA AVHRR Sensor in 1989 channel 14 and 15 (multichannel) were used to drive the SST algorithm [3]. For identifying the PFZ, the SST images are not always adequate for identification and the ocean color sensor can give chlorophyll as an index of phytoplankton distribution in the ocean. Indicators of PFZ like ocean color sensor like OCM can observe thermal and chlorophyll fonts. Integration of ocean color with SST has enhanced the ability to detect oceanic features in tropical water which can be correlated with fish shoal which made possible to identify new fishing grounds. At present, the fishing activities are concentrated to a narrow belt of inshore waters up to a depth of 50mts. In the application of Remote Sensing application satellite remote sensing is very important due to Coastal Zone Color Scanner, Infrared Thermal Data, and Scatterometer wind stress measurements. Chlorophyll concentration data is retrieved from MODIS Sensor with help of TERRA Satellite and SST concentration is retrieved from AVHRR sensor with help of NOAA-18 satellite for different targeted species and these features transferred on to a scaled based map called an 'Integrated Potential Fishing Zone Map'[4].In marine fisheries habitat, fishes are known to congregate in temperature boundaries therefore surface circulation features like location and evolution of frontal boundaries, upwelling zones, current eddies etc. are important. The information of these parameters is derived from satellite and from in-situ platforms. The scientific communities make use of these parameters and thus evolve the scientific indicators of PFZ, this information were derived from satellite and in-situ platforms. To maintain fish stock at level and to conserve the fishery health, a uniform ban on marine fishery has been imposed by Government of India along west coast from 10 June to 15 August. It is also interesting to note that Ratnagiri off have been paid less attention as far as Remote Sensing and Image processing studies are concerned which is reflected in low number of publications from these regions. The main objective of the study is to discuss the benefits of Remote Sensing for PFZ with help of 
image processing techniques/software such as ArcGIS (Arc Geographical Information system), ESRI (Environmental Systems Research Institute), ENVI (Environmental for Visualizing Images), ERDAS (Earth Resources Data Analysis System), and R Tool Package for melioration of fishermen community and for technology.

\section{Different Technologies For Identifying Potential Fishing Zone}

To avoid the traditional method of fish catch for identifying the PFZ, to avoid laborious work of fishermen, to reduce man power and to reduce the fuel consumption of trawlers the satellite remote sensing technology with help of image processing techniques is adapted. Satellite data extraction is done by various image processing techniques.

1] ArcGIS (Arc Geographical Information System): A Geographical information system is a system for the management, analysis and display of geographic information. Geographical information is represented by a series of geographic datasets that model geography using simple data structure. In a general sense, the term GIS describes any information system that integrates, stores, edits, analyzes, shares and displays geographic information for informing decision making. The Geodatabase view, Geovisualization view, Geoprocessing view is represented in ESRI ArcGIS by the Catalog, the Map and Tool box. Diagrammatic representation of 3 Views of GIS.

\begin{tabular}{|c|c|c|}
\hline Geoprocessing & Geovisualization & Geodatabase \\
\hline Models & $\downarrow$ & $\downarrow$ \\
Daps & $\downarrow$ \\
\hline
\end{tabular}

Fig. 1: 3 Views of GIS.

GIS organizes geographic data into series of thematic layers and tables. A GIS network is an implementation of an SDI (Spatial data infrastructure) and has 3 keys building blocks:GIS User Community, GIS Catalog Portal, and GIS Services. ArcGIS can be used in a waste water department prioritizes area for repair after an earthquake; An engineering department monitors the condition of road and bridges and produces planned maps for natural disasters; A water resource management traces upstream to find the possible sources of a containment[5]. ArcGIS includes Internet capabilities in all Esri software products. The services, provided through ArcGIS Online at www.arcgis.com, include web APIs, hosted map and geoprocessing services, and a user sharing program.

2] ESRI (Environment Systems Research Institute): ESRI, the global leader in geographic information systems (GIS) has officially released ArcGIS Online for Organizations, a groundbreaking service that offers expanded collaboration tools for cataloging, visualizing, and sharing geospatial information. ESRI also offers ArcGIS Runtime SDKs for building and deploying custom mobile mapping applications. These SDKs are integrated with the ArcGIS system and make developing, testing, and deploying applications faster and easier. They combine geospatial data and maps into intuitive mobile applications [6]. ESRI inspires and enables people to positively impact their future through a deeper, geographic understanding of the changing world around them. The company was founded as Environmental Systems Research Institute in 1969 as a land-use consulting firm. ESRI products (particularly ArcGIS Desktop) have 40.7\% of the global market share. In 2014, ESRI had approximately a 43 percent share of the GIS software market worldwide, more than any other vendor. The data format is in Vector and Raster form. Shapefile - ESRI's somewhat open, hybrid vector data format using SHP, SHX and DBF files. ESRI's grid - binary and Meta data less ASCII raster formats. ESRI Demographics is used for mapping and analysis purposes. ESRI Demographics supports commercial market analytics and noncommercial usages, such as economic development, planning, and at-risk population assessment. ESRI Demographics is accessible in four ways: dynamic web maps, data enrichment, reports, and info graphics. ESRI is generally used for land imaging due to its suitable packages which are compatible for user to work on such areas.

3] ENVI (Environment for Visualizing Images): ENVI uses a graphical user interface (GUI) to provide pointand-click access to image processing functions. ENVI file format uses a generalized raster data format consisting of a simple flat-binary file and a small associated ASCII (text) header file. This file format permits ENVI to use nearly any image file, including those that contain their own embedded header information. ENVI also supports a variety of data types: byte, integer, unsigned integer, long integer, unsigned long integer, floating-point, double-precision floating-point, complex, double-precision complex, 64-bit integer, and unsigned 64-bit integer [7]. Environmental Studies concerns a variety of critical issues that face the world: Climate change, The sustainability of our cities, transport, and energy systems, Living systems and resources - water, air, soils, biodiversity ,Indigenous, understandings of humans in nature, Globalization and consumerism , Inequality. There are various codes which are useful to study different categories: ENVI 522-Environmental and Planning law, ENVI 524- Environment Economics for Policy, ENVI 528- Climate change issues, ENVI 529- 
Sustainable energy, GEOG 410- Urban Studies, PHYG420- Hydrology and Water Resources. ENVI is generally used for the Environmental parameters for researchers.

4] ERDAS (Earth Resources Data Analysis System): ERDAS Imagine is a remote sensing application with raster graphics editor abilities designed by ERDAS for geospatial application. In ERDAS IMAGINE, bands of data are occasionally referred to as layers. Once a band is imported into a GIS, it becomes a layer of information which can be processed in various ways. Additional layers can be created and added to the image file (.img extension) in ERDAS IMAGINE, such as layers created by combining existing layers [8]. ERDAS IMAGINE is the world leading geospatial data authoring software. The products of ERDAS add-ons are licensed separately. File Coordinates and Map Coordinates are two basic coordinate system used in ERDAS Imagine. The File coordinate indicates location of a pixel within the image and Map coordinate indicates the location of pixel in a map. ERDAS supports 8 bit pseudo color, 15 bit hicolor, 24 bit direct color and 24 bit true color displays. For finding PFZ the software/packages which are required are very expensive and the programming is also complicated which makes ERDAS difficult for researchers to use.

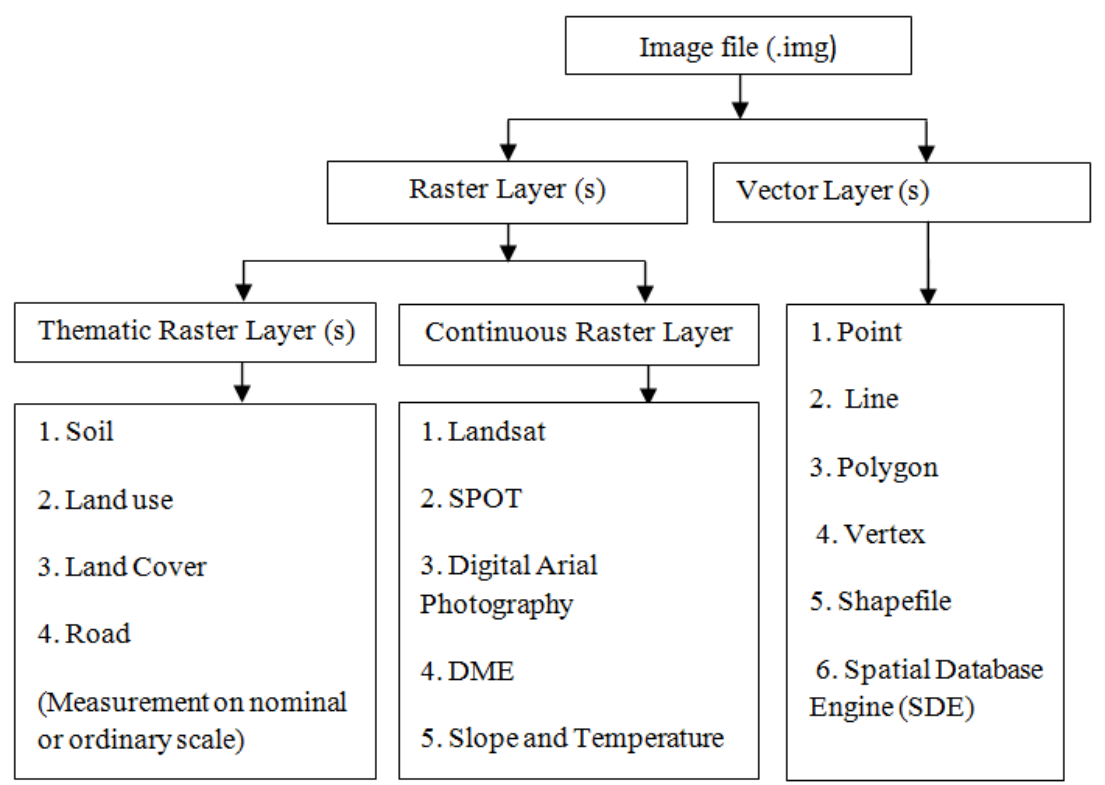

Fig. 2: Block diagram of ERDAS Imagine.

5] $\mathrm{R}$ Tool: $\mathrm{R}$ is very much a vehicle for newly developing methods of interactive data analysis. It has been extended by a large collection of packages. Most of program written in $\mathrm{R}$ are essentially ephemeral, written for single piece of data analysis. $\mathrm{R}$ Tool Environment is an integrated suite of software facilities for data manipulation, calculation and graphical display. It has an effective data handling and storage facility. The term Environment is intended to characterize it as a fully planned and coherent system, rather than an incremental accretion of very specific and inflexible tools as is frequently the case with other data analysis software. $\mathrm{R}$ operates on named data structures. The simplest such structure is the numeric vector which is a single entity consisting of an ordered collection of numbers. R consists of 3 things: Project, Language, Software Environment [9].It also has 3 parts: The body ( ) the code inside the function, the formals ( ) the list of arguments which controls how user can call the function, the Environment ( ) the map of the location of the function variable. $\mathrm{R}$ Tool consists of Raster, Leaflet and Shiny data for its working. Raster package provides classes and function to manipulate geographic (Spatial) data in raster format. Raster data divides space into cells of equal size; such continuous spatial data are also referred to as grid data. The package should be particularly useful when using very large datasets that can be loaded into the computer memory. Function will work correctly because they process large files in chunk that is they read, compute and write block of data without loading all values into memory at once. Leaflet package adds graphical element and layers to the map widget. It adds a raster image as a layer. Shiny package make it incredibly easy to build interactive web application with R. Its automatic reactive binding between input and output and extensive prebuilt widgets makes it possible to build beautiful responsive and powerful application with minimum effort. With help of R Tool the SST and Chlorophyll-a concentration will be calculated due to primary component of food chain is phytoplankton. Phytoplankton growth depends on the sunlight and cold water. While finding the PFZ location SST and Chlorophyll-a concentration is calculated from Wave Rider Buoy (WRB) which is deployed in open sea of Ratnagiri region. The data which is obtained from WRB and INCOIS official website is then processed to get the PFZ location of particular region by selecting its latitude and longitudinal position. 


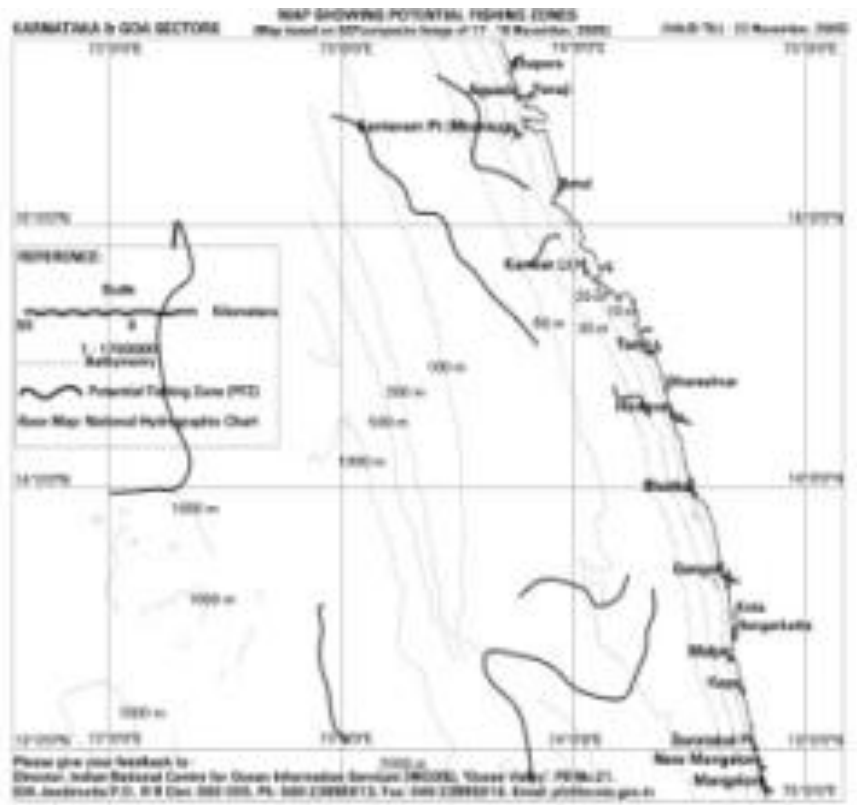

Fig. 3: PFZ map of Maharashtra.

Figure 3 shows the PFZ location of Maharashtra region for fisherman community to simplify the catch with time series location of Ratnagiri region.

\section{Proposed System}

This is the proposed system for locating PFZ:

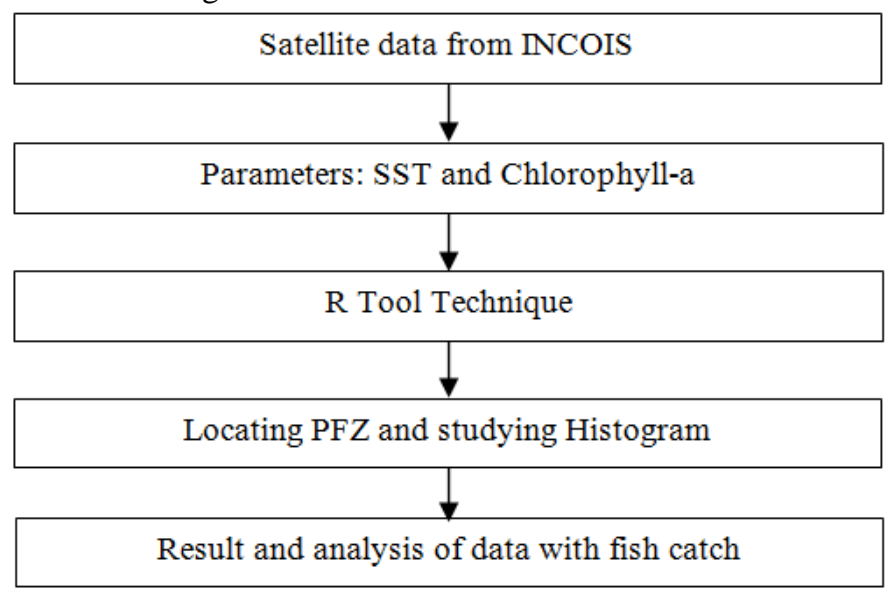

Fig. 4: Proposed system for finding PFZ location.

TERRA satellite along with MODIS sensor is required for calculating the Chlorophyll-a concentration and NOAA-18 satellite along with the AVHRR sensor is used for calculating the concentration of the SST. These parameters are available from INCOIS official website[10]. After downloading this data in image form (geotiff. image) and obtaining the excel sheet of forecast validation, $\mathrm{R}$ functioning is processed for getting the PFZ location. Along with the PFZ location in graphical format, the latitudinal and longitudinal position will be visible in image near to Ratnagiri location of west coast. The forecast validation along with the SST and Chlorophyll-a concentration reading will also be available histogram format for further study and analysis of data. This will help to locate the PFZ and will be beneficial to get good fish catch with less time and fuel. Due to nature of data storage technique data analysis is usually easy to program and easy to perform. The inherent nature of rater map example one attribute maps is ideally suited for mathematical modeling and quantitative analysis. 


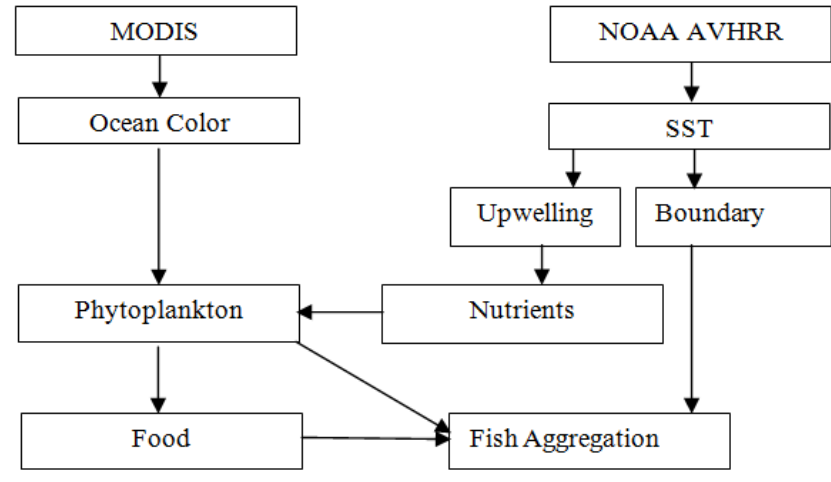

Fig. 5: Fish Finding with Remote Sensing Approach

Phytoplankton is the basic food of fish from which the chlorophyll is detected which helps to analyze the ocean color. The WRB which is deployed by INCOIS acts as a high frequency transmitter to calculate different parameters related to sea with help of NOAA AVHRR (National Oceanic and Atmospheric Administration Advance Very High Resolution Radiometer)

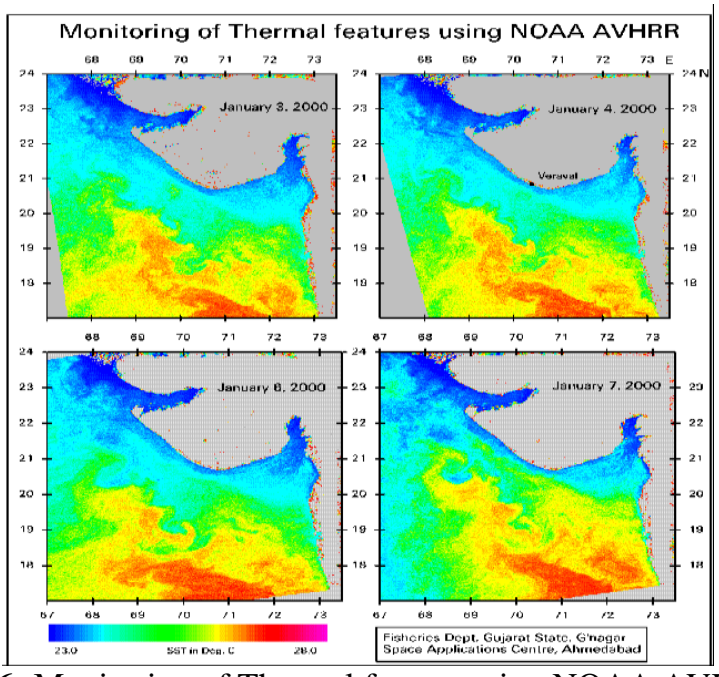

Fig. 6: Monitoring of Thermal feature using NOAA AVHRR

From Figure 5 Monitoring thermal features images after manipulating is used for integrated potential fishing zone. Fishes are attracted to the sudden change in temperature so SST will be calculated with help of different temperatures in sea water boundaries and through upwelling currents which usually brings nutrientladen towards the surface will help for fish aggregation. From these parameters PFZ location is calculated and fish catch can be increased.

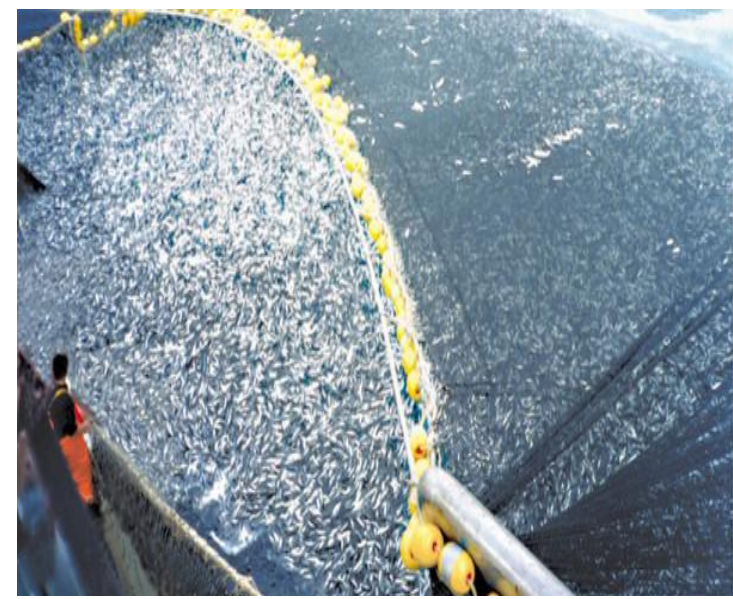

Fig. 7: Fish catch in PFZ 


\section{Conclusion}

Generic additive model have shown the capability to predict the PFZ for Ratnagiri. With help of R Tool and Remote sensing application PFZ location can be find which will increase the fish catch. For identifying the PFZ to avoid the traditional method of fish catch, to avoid the fuel consumption and to save time the satellite remote sensing technology along with the image processing techniques is adapted. In this paper we have discussed different image processing software along with its uses and have given special attention to $\mathrm{R}$ tool along with its packages. A state of art database driven user friendly dynamic website with advisory services such as PFZ was developed with help of R. INCOIS has been prime component for delivering of ocean data for $\mathrm{R}$ operation.

\section{Acknowledgements}

I would like to say thanks to Dr. Abhilasha D. Mishra M.I.T College, Dr. B.A.M University authorities, INCOIS authorities for their support at various

\section{References}

[1] Nammalwar.P, S.Satheesh and R. Ramesh," Indian journal of geo-marine sciences" vol.23 (3) June 2013, pp.283-292.

[2] Tom Garrison and Robert Ellis, "oceanography: An invitation to marine science/9e" pp.25 - 26, 2014.

[3] George Joseph, "Fundamental of Remote Sensing"2nd Edition"pp.384-387.

[4] S.B Choudhury, B. Jena, M.V Rao, K.H Rao, V.S Somavanshi, D.K Gulati and S.K Sahu,"Validation of Integrated potential fishing zone(IPFZ)forecast using satellite based chlorophyll and sea surface temperature along the east coast of India"IJRS Volume 28,no.12,20 June 2007,2683-2693.

[5] Bob Boothand Andy Mitchell, "Getting started with ArcGIS."

[6] Arc India News, ESRI India Magazine, April-June2012, Volume 6, Issue 2

[7] ENVI Tutorial: Introduction to ENVI.

[8] ERDAS Field Guide, Fifth Edition, Revised and Expended, Atlanta, Georgia

[9] "Statistics using R with biological examples" by Kim Seafeld and Einst Linder, University of New Hampshire, Durham, May 2007.

[10] www.incois.gov.in 